\title{
The Pedagogy of Creative Placemaking: A Field Begins to Come of Age
}

VICTOR RUBIN

PolicyLink

\section{MARIA ROSARIO JACKSON}

Arizona State University

Creative placemaking has been evolving from a narrow definition of applying art and design ideas to community projects into a more expansive, equity-focused field of practice. As the funder consortium ArtPlace America describes it, "Creative placemaking happens when artists and arts organizations join their neighbors in shaping their community's future, working together on place-based community outcomes. It's not necessarily focused on making places more creative; it's about creatively addressing challenges and opportunities.... creative placemaking at its best is locally defined and informed and about the people who live, work, and play in a place."

Many architects, given their training, roles, interests, and values, are working in the midst of this explosion of creativity and innovation. A recent analysis by a leading management firm concluded that "the creative placemaking field in this country is 'moderately strong.' .... Over the last 7 years we have steadily developed a shared identity among a group of practitioners who would not have previously defined their work as being part of the same field; we have added both to a knowledge base and to standards of practice, and we have been able to identify, support, and engage leaders, practitioners, funders, and policy makers."

The ACSA 2019 Fall Conference at Stanford University provided the opportunity to examine emerging trends in the teaching of creative placemaking. The session at Stanford had its roots in a convening which took place on January 29 and 30, 2019 in Phoenix, cosponsored by Arizona State University and ArtPlace America. Sixty-five leading creators of the emerging pedagogy of creative placemaking were convened by the Herberger Institute for Design and the Arts at ASU to take stock of the state of their practice and set a course for its improvement. ${ }^{1}$ They were joined in this effort by grass-roots organizers, artists experienced in social and civic practice, and supporters in philanthropy. This unique meeting and its associated surveys of participants generated a deep well of findings and observations about what the pedagogy of creative placemaking will need to reach its potential. Victor Rubin, the public director on the ACSA Board of Directors and a researcher on arts, culture and equitable development at PolicyLink, participated in the convening, along with its co-chair Maria Rosario Jackson, Institute Professor in the Herberger Institute, and Theresa Hwang, architect, principal of the Department of Places and

\author{
CELINA TCHIDA \\ Arizona State University
}

\section{THERESA HWANG}

Dept. of Places

Program Director of the Design Futures Student Leadership Forum. Celina Tchida, doctoral student at ASU, helped to organize and document the convening and provided the notes and analysis used further on in this account.

As the field of creative placemaking has expanded, so too has the need to develop a distinct and productive way of teaching it. The teachers of creative placemaking come from programs in architecture, urban planning, arts administration, fine arts, public policy, and nonprofit management. The exploration in Phoenix was initiated by these four sets of questions:

- How do you define creative placemaking and how do you distinguish equitable creative placemaking practices from those that do not lead to equitable outcomes in communities?

-What are core competencies for this work?

-What are ethical considerations particular to teaching and/or engaging in creative placemaking in communities?

- In the context of teaching creative placemaking, what are some of the challenges you face inside and outside of the classroom? What are opportunities to advance the work?

The discussion was strengthened by the participants' critical analyses of power, race, the nature of design expertise, and the changing dynamics of neighborhoods and cities.

In the session at Stanford, Rubin briefly described the evolution of creative placemaking from a narrow definition of applying art and design ideas to community projects into a more expansive, equity-focused field of practice. He located the ASU convening in that context and introduced the four questions shown above. Then, Rubin introduced a set of eight "competencies" needed by community developers if they are to be effective at incorporating arts, design and culture into their work. The competencies were put forward in the convening by Lyz Crane of ArtPlace America, based on her experience directing the Community Development Investments initiative (CDI), a program of grants and technical support for six diverse community development organizations to develop and incorporate arts and culture strategies to advance their missions. The list of competencies includes:

\section{Conceive Arts-based Opportunities}


2. Understand and Map Cultural Fabric of Community

3. Align Internal Assets

4. Secure External Capital

5. Realize Partnerships

6. Facilitate Community Processes

7. Learn and Iterate

8. Communicate

Rubin, who has been documenting the CDI process since $2015,{ }^{2}$ noted that these are qualities which would be highly relevant for architects participating in these kinds of endeavors. They reflect a body of knowledge and set of skills by which the contributions of designers can be grounded in local identity and interactive with community interests, and more likely to raise the resources and build the partnerships necessary to see complex projects through to completion.

The CDI process unleashed a wave of creativity among the community developers as they connected with local artists, and Rubin described one such activity undertaken in Anchorage, Alaska by the Cook Inlet Housing Authority, a tribal housing organization, with local artists Becky Kendall and Enzina Marrari. "Mime Spenard" transformed the public spaces of this neighborhood during a disruptive, fragmenting period of road reconstruction into an engaging, uplifting summer-long sequence of community-building actions and artistic projects punctuated by the unexpected appearances of an evergrowing array of professional and volunteer mimes. Not your conventional citizen engagement process! Outcomes included

- Reframing how public art can happen within the Municipality

- Increasing cross sector partnerships

- Maintaining the identity of Spenard

- Increasing opportunities for artists

The six CDI local grants generated scores of projects in architecture and interior design, visual arts, performing arts, storytelling, historical studies, and other forms of expression. Each was tied to a larger strategy for preserving or uncovering community identity, supporting neighborhood revitalization, promoting health equity and positive youth development. They arose from indigenous, African American, Latinx, and Asian American cultures in rural and urban communities.

The remainder of this proceedings is comprised of a partial record, compiled by Celina Tchida of the Studio for Creativity, Place and Equitable Communities at ASU, which reflects key themes of that convening in Phoenix, including the remarks of faculty members and community leaders and summaries of small group discussions.

\section{INTERVIEW WITH DEAN STEVEN TEPPER AND DEAN}

\section{JONATHAN KOPPEL}

Steven Tepper, Dean of the Herberger Institute for Design and the Arts (HIDA) and Jonathan Koppel, Dean of the Watts College of Public Service and Community Solutions were interviewed by Dr. Maria Rosario Jackson. Dr. Jackson asked the deans about the challenges and opportunities inherent in committing to integrating creative placemaking into their respective curricula.

Questions the deans raise in thinking about change in academia

- Is it a course? Can you find room in your curriculum, what are you going to give up? Can it be done as a unit of content into multiple courses? How much do you have to be exposed to do it responsibly?

- None of that is even worth pursuing if you don't have a story to tell about why you think it's important. In order to convince students OR faculty. What is the value added? Why do the extra work to incorporate?

- It can't live with a single faculty member and more importantly it cannot just be driven by deans. How do a set of practices become part of how faculty are thinking? The distinctiveness is that success is ability to sustain - it has to have its own weight, but it has to be owned across sectors/industries/disciplines.

- Who's waking up thinking, that's their job? Sometimes you need someone from a neutral or multiply affiliated position to be able to work and knit and connect. That was the vision for the Institute Professors at HIDA.

Industry standards have to change

- What we aspire to is different from what people are on the hook for professionally. In CD it's usually blunt measures of economic development that are celebrated. With $\mathrm{CP}$ it leads to things like agency, stewardship, restoration of things that have been stripped away, CD is not on the hook for that. How does an institution think about affecting industry standards?

Rewards and recognition

- Teaching CP and institutional culture shift requires more time and more effort and without the same "impact" as traditional faculty responsibilities so how will you reward and provide recognition to enable this?

- Institutions don't leverage recognition tools enough. For tenure, we often perceive it as a system outside of our control. But we make decisions about who we are soliciting ideas from. How is the work documented? Tenure is identifying peers saying the work they did is important. How do you make CP work legible and understood as valuable?

- The promotion and tenure process is owned by faculty. If the promotion and tenure criteria say $X Y Z$, you are constrained. Faculty need to reexamine how we evaluate that. Most promotion and tenure processes rely on 
set standards of impact; we use citations. How might stories about community impact count? You have to make explicit the connection between teaching, research, etc. Part of the question is 'how do you make sure that what you're doing is rooted in scholarship and produces outcomes that can be measured?'

Role of the research university

- What does knowledge constructed in an academic way do for you? Part of what higher education can do and does do - is get past the anecdotal and experiential to create something generalizable that the student can draw from. That's the point of having a field. Extrapolated knowledge that can be imported in different contexts. How do you import general knowledge into specific circumstance? That has to be part of pedagogy.

- If a university is a partner it's important to think of the community as Co-PI, not just the subject for study. There has to be openness about a joint process. The work has to be about discovery just as much as product.

\section{EXPLORATION ONE: CORE COMPETENCIES}

In this session, panelists drew from their diverse experiences and put forward their best thinking about core competencies for equitable creative placemaking. The following are core competencies put forth by Dr. Maria Rosario Jackson, Arizona State University. ${ }^{3}$

- Historic Equity and Power Analysis: the conditions of a community are the result of these dynamics over time

- Critique of Conventional Community Development Planning and Related Approaches

- Expansive Lens for Arts, Culture and Design: definition must go beyond only professional arts, art as product and art consumption

- Understanding of the Alignment and Effectiveness of Specific Arts and Cultural Practices in Relation to Community Development and Related Goals

- Dexterity Across Diverse Siloes of Policy and Practice

- Asset-based Approach to Community: important premise but MUST also be critiqued so as not to have a naïve or reductionist understanding of complex historic power dynamics. Notion of trauma-informed work is useful for this. Some communities have complicated relationships to place.

- Resident Activation, Co-production and Co-creation: supporting the agency of people in place is central to this work as is recognizing the systemic sources that preclude agency (often can be generational); "co-production" has to be interrogated for ethical practice.

- Knowledge of Resources to Sustain Creative Placemaking

- Evaluation and Communication: important, but difficult because it is cross-disciplines and some of the things that creative placemaking contributes to are not yet the things that community developers and planners most commonly view as metrics or markers for success

- Identifying, Codifying and Making Work Visible

- Institutional Systems Change and Accountability: Identification of Leverage Points and Disruption of Industry Standards, as needed

- Building a Culture of Creativity and Risk Taking

Following presentations, small groups of about 8 people were asked to identify and discuss the 7-10 core competencies that they feel are most important, consider the parameters of an introductory creative placemaking experience in college or university and also the kinds of course work that should follow an introductory experience. This is a compilation of thoughts from the small groups:

- Place

o A course that covers who was here first, what a local community has looked like throughout history up to today-something that helps students see themselves (often) as ethical visitors in their collegiate communities.

o We must teach about the policies that have and still are shaping public and private spaces, communities, etc. - the social, cultural, racial and political history.

- Self-Assessment

o What you bring to the table

o Your biases

o Where you can stand in your expertise and where you need to fall back

- What Arts and Culture Includes

o An expansive, decolonized interpretation of the arts is necessary

- Equitable Community Planning and Development

- Analysis of Systems of Power

o Understanding how power is built and power dynamics within communities - critique of power in place and power analysis (thinking about systems)

o Cross sector collaborations/working within complex systems

o How we relate to where/who we are at a specific table

- Entering Communities and Partnership

o Understanding questions that need to be asked, appetite for discovery and understanding of product vs. process

o Asset-based approach/value of local knowledge

o Understanding how to create community trust 
o Critical thinking skills

o Collaboration and relationship building - the ethics of engagement

o Facilitation training

o Code switching

o Sustainability, resources, funding

o Understanding ladders of engagement. From engagement to empowerment.

- Issues to consider when creating a course

o What education has to happen for the faculty?

o We need to be considering faculty as the students in this case, because we're finding that there aren't enough people in academia identifying themselves as doing this work.

o There should be some consideration to who is being taught and how. What level of students? Masters or bachelors? Other?

o Where are the practitioners/those who don't want to get a degree or certificate?

o Local artists - where do they fit?

o Understand who an artist is/how are people defining their work

Instruction Design and Designers

- Who is most qualified to design a course? Community members? Artists doing work? Other?

- Co-authorship, co-curation, and co-creation should be considered as should equity of validation and credentialization that can create barriers and reinforce inequity. How do we share power - with students and with community? Can we fit this into continuing education and more practice-based institutions?

- Sovereignty, especially in some communities, is a fundamental issue as well.

- Center indigenous, black, women of color, queer, explicitly de-centered whiteness, collective identities-multiplicity

- At times, faculty must know how to step back and facilitate contribution of expertise of others

Types of Resources and Structure of class

- Case Studies

- Archival material

- Stories/storytelling

- Readings

- Guest speakers

\section{EXPLORATION TWO: INSTITUTIONS AND}

\section{COMMUNITIES}

Faculty members Wanda Dalla Costa (Architecture, ASU), Dr. Barbara Brown Wilson (Urban Planning, University of Virginia), Dr. Andrew Zitcer (Arts Administration, Drexel University), and Dr. Maribel Alvarez (Folklore and Anthropology, University of Arizona) presented learnings, values and principles they have taken from their respective work. This is a compilation of takeaways from these presentations.

The work should be...

- Experiential, communal, holistic

- Place-based

- Process-based-process over product

- Driven by the people who are most impacted (community sets the table)

It is important to...

- Understand the deep history to understand the realities of place

- Reorganize power

- Question the assumption that engagement by the university is always good

- Flip the analytical gaze on universities/institutions

- Draw from a trauma-informed care perspective

- Budget equitably, not just make promises of benefit to community

- Play the role of the "rear guard," facilitating from behind and not center the university (but know this can be difficult with funders and institutions)

- Check in and having an ongoing dialogue about the partnership-- it's a lot for the community to be invested in doing these for the long-haul.

- Under-promise and over-deliver

- To incorporate students, the work has to be highly modular, and goals need to be structured in a sustainable method for the framework of the project... Build a structure that communities can trust will remain in place, with staff and faculty being more consistent, allowing students to migrate through the program

- Re-center and de-center critical conversations so that community members become the new partners in creating and envisioning new futures.

Consider...

- The neighborhood may not want us as much as we want to help them

- Industry standards create tension between creative placemaking and established learning objectives in arts management programs 
- It can be difficult and important to make mid-course corrections through engagement with the community partners. (Don't let the syllabus hold us back.)

- The contours of power, production, economics, politics, and the relationship our institutions have to that legacy

- That harm has likely been done, can continue to be done and consider what that means for accountability

\section{REFLECTIONS FROM PRACTITIONERS/NON- ACADEMIC PARTICIPANTS}

If we are to carry out equitable community engagement or more insular pedagogy, we must be accountable to folks outside of academia. Several non-academic participants generously shared some of their reactions and reflections from the meeting. Space constraints preclude including all of their remarks, but the excerpts from practicing architect Theresa Hwang that follow are reflective of what was appreciated as well as the distance still to be traveled in order for academic efforts to teach and advance creative placemaking to be respectful, relevant, and valuable to marginalized communities, especially communities of color.

Theresa Hyuna Hwang, Architect, Founder and Director of the Department of Places in Los Angeles and program director for the Design Futures Student Forum reflected on what she had heard throughout the convening:

I have a lot of gratitude for collective reflection, realizing how precious that is. Thank you for your energy and attention. I was really happy to hear the conversations around trauma and how it manifests in the built environment, our communities, and neighborhoods.

Just last week I was in an all-day trauma and resiliency training. I got to that through trauma-informed parenting classes as a way to start addressing my own adverse childhood experiences and thinking about intergenerational trauma that I don't want to transmit to my daughter, then realizing that our neighborhoods are spaces of collective trauma. To think about that a little more out loud has been helpful.

$\mathrm{CP}$ at its best is disrupting white supremacy in the built environment [snaps from audience] a lot of times CP is making visible the culture that has been there for generations connected to the ancestry of place, but white dominant culture strips culture from publicness and so I think at its best CP is a way to potentially heal and recover but also resource communities so they can live out loud, manifest and see themselves in the built environment.

In addition to the way that trauma manifests in our neighborhoods, the academy and school are also intense places of trauma. Speaking from my own architecture experience, people ask why there aren't more people of color [in the field], and it's because it wasn't designed for us. It's not a system that was set up for me to actually do well. And I don't use the word trauma lightly, but I am realizing now that I had an intensely traumatic experience [in graduate school], prolonged four years of crying frequently, [doubting my abilities as a result of harsh critique], that has an impact.

I learned to shift the question in trauma-informed care from 'what's the matter with you?' to 'what happened to you?' When you ask, 'what happened to you?' that's kind of getting at the systems of harm that you have no control over that you've been impacted by.

When I think about school as a place of harm, it's a place of self-doubt, it's not nurturing. Right now, I feel thankful to be in a room of educators, so we can ask each other 'how are we actually countering the trauma of the white supremacy that is manifesting in our pedagogy?' Thinking about school, the institution as a place of intervention and not always our neighborhoods and putting that back on people who are the most impacted becomes an interesting question.

We were joking at lunch that CP needs to happen in wealthy white suburbs: when you talk about equity, [education, and self-awareness to biases to prevent perpetuating harm], that's the place of intervention that actually needs to happen. Why is CP always in low-income communities of color? So, some of that reframing [is needed.]

I think we talk a lot about de-centering and re-centering and I guess my last question/comment/thought: we always say we need more seats at the table, but what if that table is in a harmful room? So, I think we need to start asking the questions about the invisible shells and systems that we're all interacting in. Maybe we need to just burn it all to the ground and build a playground outside and we just need to play. 
Hwang's reminders of the intense and serious impacts of collective trauma and systemic racism in the arena of design are a fitting way to close this account of how many leaders in creative placemaking are repositioning this body of work. The necessary tasks are not only those of generating a lively, relevant curriculum, building authentic community partnerships and being open to new methods of teaching. There are bigger structural challenges that must also be taken on, both in the awareness of students and faculty and in the institutions of higher education.

\section{ENDNOTES}

1. The convening was a project of the Studio on Creativity, Place and Equitable Communities of the Herberger Institute at ASU. (https://herbergerinstitute. asu.edu/research-and-initiatives/creative-placemaking)

2. The research about, and documentation of, the Community Development Investments initiative can be accessed online at https://communitydevelopment.art/.

3. The ways in which Arizona State University is expanding its own competencies and reach in this field is described in this piece by Steven J. Tepper, Dean of the Herberger Institute for Design and the Arts: https://medium.com/ herberger-institute/national-design-and-arts-based-equitable-developmentand-practice-for-public-good-at-arizona-state-cf4986b050a8. 